\title{
AN ERRORS ANALYSIS IN USING TENSES OF STUDENTS' WRITING TEXT AT SENIOR HIGH SCHOOL
}

\author{
Syaprizal ${ }^{1}$ \\ STKIP PGRI LUBUKLINGGAU \\ Ramadona $^{2}$ \\ STKIP PGRI LUBUKLINGGAU \\ syaprizal2018@gmail.com ${ }^{1}$
}

Submit, 25-05-2018 Accepted, 10-06-2018 Publish, 10-06-2018

\begin{abstract}
The objective of this investigation was to investigate students errors in writing recount text made by the eleventhgrade students of social program Senior High School Number 1 and Senior High School Number 2 Muara Beliti in academic year 2016/2017. The method applied in this investigation was descriptive method. The subject of the investigation was all the eleventhgrade students of social program Senior High School Number 1 and Senior High School Number 2 Muara Beliti. The number of the sample was 30 that consist of five students each class and each school. To get the data, the writer used essay test. The test given was an intruction to compose a paragraph in 150 words. Based on the finding of data analysis from the test. The majority errors doneby the Eleventh Grade of Social Program Students of Senior High School Number 1MuaraBeliti was Verb $(55.36 \%)$ total errors was 62. Punctuation and spelling (4.46\%) total errors was 5. Preposition $(5,35 \%)$ total errors 6. Pronoun (34.83\%) total errors was39.The majority errors donethe Eleventh of social program Grade Students of Senior High School Number 2 Muara Beliti wasVerb (61.67\%) total errors was 37. Punctuation and spelling $(1.66 \%)$ total errors was 1. Preposition $(1.66 \%)$ total errors was 1 . Pronoun $(35.01 \%)$ total errors was 21 . In conclusion, The students did such errors because the students translated directly from Indonesian language into English. Therefore, they forgot to use the correct pattern of a sentence that consist subject, verb, and object.
\end{abstract}

Keywords: writing, errors, tenses analysis, recount text. 


\section{INTRODUCTION}

Richard (2002:592), writing view as the result of complex processes of planning, drafting, reviewing and revising and some approaches to the teaching of first and second language writing teach students to use these processes. As a result, grammar becomes aspect that is important to learn if we want to be fluent in English. Writing is the most important skill at the junior and senior high school. That is why, the emphasis of teaching English is writing. The curriculum for SeniorHigh School emphasizes that teaching writing inEnglish instruction is to develop the students' ability in writing.

Actually, Writing is a complex process that involves thinking and composing. Writing also used to express what the people have shown in life, to communicate each other directly and forcefully. It is actually an expression of life passing through language form. Many of the students usually make grammatical error in their learning especially in writing skill, such as in tenses, there are no tenses in Indonesian language so many confuse in using the right tenses for their writing. Sometimes the teacher did not aware about students' mistakes. Than students made mistake in their writing because they did not understand how to used the grammatical well.

James (1998:78) said that, if the learner is inclined and able to correct a fault in his or her output, it is assumed that the form he or she selected was not the one intended, and we shall say that the fault is a mistake. On the other hand, the learner is unable or in any way disinclined to make the correction, we assume that the form the learner used was the one intended, and that is an error.

Corder (1982:218) says that errors analysis is the study analysis of the errors made by the second of foreign language learners to predict the errors or the difficulties in learning foreign language. Error analysis may be carried out in order to find out how well someone learns a language, find out how well someone knows language, and obtain information on common difficulties in language learning.

This study tries to describe and analyze the areas of difficulties in written English in sentences made by senior High School Students. This includes errors on tenses in student's writing text. Errors on tenses viewed from morphology and syntax will be analyzed.

In the other hand, it was important by the teacher to give error analysis in students writing. Error analysis is an activity to identify, classify and interpreted or describe the errors made by someone in speaking or in writing and it is carried out to obtain information on common difficulties faced by someone in speaking or in writing English sentences. James (1998:1) states that error analysis is the way of determination the incidence, nature, causes, and consequences of unsuccessful 
language. Although errors are bad things in learning English, error analysis is advantageous for both students and teachers.

Error analysis is needed to show them in what aspect in grammar which is difficult for them, to show the errors made by the students, to know the source or the cause of the error and how the students can learn from their mistakes in order that they will not make some errors repeatedly. And for teachers, it is required to evaluate themselves whether they are successful or not in teaching English.

Based on the phenomena illustrated above, the writer conductedin analyzing students' errors in using tenses. Therefore the writer interest to conduct investigation entitled “An Errors Analysis In Using Tenses of Students' Writing Text At Senior High School”.

\section{LITERATURE REVIEW}

\section{Error and Mistake}

When learning about error, it cannot be separated from learning about mistake. Error and mistake are different, but some people still misunderstanding about the both. To make clear the distinction of error and mistake. James (1998:78) sometimes we confuse to differentiate between error and mistake. If the learner is inclined and able to correct a fault in his or her output, it is assumed that the form he or she selected was not the one intended, and we shall say that the fault is a mistake. If, on the other hand, the learner is unable or in any way disinclined to make the correction, we assume that the form the learner used was the one intended, and that it is an error.

Mistakes can only be corrected by their agent if their deviance is pointed out to him or her. If a simple indication that there is some deviance is a sufficient prompt for self correction, then we have a first-order mistake. If additional information is needed, in the form of the exact location and some hint as to the nature of the deviance, then we have a second-order mistake.

James (1998:83) errors cannot be self-corrected until further relevant (to that error) input (implicit or explicit) has been provided and converted into intake by the learner. In other words, errors require further relevant learning to take place before they can be self-corrected. According to Norrish (1987:7) error is a systematic deviation, when a learner has not learnt something and consistently gets it wrong It seems that the phrase 'systematic deviation' in these definitions is a key word which can be interpreted as the deviation which happens repeatedly.

Richards (1973:98) stated that mistake is made by a learner when writing or speaking which is caused of lack of attention, fatigue, carelessness, or other aspects of performance. Based on the explanation, it can be stated that a mistake is the something made by students product in communicating especially in writing 
and speaking because they do not apply the rules, in other words, a mistake is a non systematic deviation from the norms of the language.

James (1998:83) stated that error is unintentionally deviant and not selfcorrigible by its author. Then, errors are the result of some failure of performance. Besides, errors can not be self corrected until the relevant (to the errors) input (implicit or explicit) has been provided and converted into intake by the learner. In other word, errors require fatherrelevant learning to take place before they can be self-corrected.

There are two ways suggested to distinguish between an error and mistake. The first one is to check the consistency of learners performance. If he sometimes uses the correct form and sometimes the wrong one, it is a mistake. However, if he always uses it incorrectly, it is then an error. The second way is to ask learner to try to correct his own utterance. Where he is unable to, the deviations are errors; where he is successful, they are mistakes Ellis, (1997:263)

\section{The Concept of Writing}

English learners should master all skills in language. They are listening, speaking, reading and writing. They are integrated skill. All of them are important but writing is the skill which is the most interesting because not everyone can write for academic. Writing is a skill that is required in many context throughout life. It means writing is a way for transferring idea or thought therefore it can be as communication tool. According to Hornby (1987:996) writing is to make letters or other symbols (ideograph) on a surface. It means that writing is the representation of language in a textual medium through the use of a set of signs or symbols (known as a writing system). It is distinguished from illustration, such as cave drawing and painting, and the recording of language via a non-textual medium such as magnetic tape audio. According to Oshima (1991:3) Writing is not easy itmakes study and practice to develop this skill. For both native speakers and new learners of English, it is important to note that writing is a process, not a product. In writing, any idea that wants to advance must be supported with specific reasons or details.

According to Harmer (2012:31) writing is often not time-bound in the way conversation. When writing, students frequently have more time to think than they do in oral activities. According to Nunan (2003:88) has defined that writing as series contrast: it is both a physical and a mental act, its purpose is both to express and impress and it is both a process and product.. From the definitions above, it can conclude that writing is the way or the process to explore writer's knowledge into a textual medium by following the linguistic rules. Writing skill for foreign learners is the most challenging activity because it is a complete that involves knowledge, concepts and writing's rules. Moreover, for second and foreign 
learners, the difficulty in writing does not only lie in creating and organizing ideas but also translating the ideas into readable writing. It stated that through writing many information and knowledge can be shared, therefore writing can develop human's life. While, writing in the sense of learning English is a challenging activity for foreign language learners because the FL learners not only have to interpret the idea into comprehended text but also they have to focus the writing's rules. However, writing reflects the FL learners competency because it can be such a tool that gives feedback in the learning process.

\section{The Tenses Errors in Writing}

The tenses errors that are found in the students' writing:

\section{Verb Tense}

Verb tense is the verb used to indicate the time at which the action or statment is occurs. Tense in English identifies when an event happens or describes a state. The simple past indicates that an activity or situation began an ended at a particular time in the past. We use past tense to describe and narrate an event or situation that occurred in the past and is over. For example: "when I was twelve, I broke my leg. I slipped on the playground on a cold winter morning and fell. The bone near my ankle snapped with a loud "pop!" Even my friends heard it. The teachers called my parents, who came quickly. Verb is a word or phrase that describes an action, condition or experience. Verbs that are not followed by an object are called "intransitive verbs." Common intransitive verbs: agree, arrive, come, cry, exist, go, happen, live, occur, rain, rise, sleep, stay, walk. Verbs that are followed by an object are called "transitive verb."

\section{Pronoun}

A pronoun is a word that is used in the place of a noun or noun phrase. Usually when a noun or noun phrase has been used once, a pronoun is used to avoid repetition of the same noun or noun phrase. There are several types of pronoun, such as Personal pronouns, intensive, indefinite, and relative pronoun.

Personal pronouns are words such as:

1. First person pronouns, example words that represent or include the speaker or writer. Singular :I, me, my, mine, Plural : we, us, our, ours.

2. Second person pronouns, example words that represent the person or people who is/are being addressed. Singular :you, your, yours, Plural : you, your, yours.

3. Third person pronouns, example words that represent people or things other than the speaker/writer and the listener/reader. Singular :he, him, his, she, her, it, its, Plural : they, them, their, theirs. 


\section{Preposition}

Norrish (1987:288-291) Preposition have been called the biggest little words in English.They are usually quite short and significant looking, but they have very important functions. Prepositions are always followed by nouns (or pronouns). They are connective words that show the relationship between the nouns following them and one of the basic sentence element: subject, verb, object, or compliment. They usually indicate relationships, such as position, place, direction time, manner, agent, possession, and condition, between their objects and other parts of the sentence.

\section{Punctuation and Spelling}

According to Grenville (2001:210) Punctuation is the use of special marks that you add to writing to separate phrases and sentences, to show that something is a question, etc. Punctuation is not something you impose upon a sentence after you have written it out. Commas, semicolons, and the other marks are an intimate part of grammar and style.

To write well, you must punctuate well; but to punctuate well, you must also write well. Punctuation mark used in punctuation, for example: full stops/periods, commas, semicolon, question mark, apostrophe, capitalization, etc.

According to Kreml (2004:388-389 ) Spelling words in English can be difficult for learners because sometimes a word is very similar to a word in their own language but is not spelled the same. For example, spell success with only one 's', or colleague without an 'a'.

\section{RESEARCH METHOD \\ Research Design}

This research the writer applied descriptive qualitative method, Isaac and Michael (1985:18) state that descriptive qualitative method is the one that describes systematically the fact and characteristics of a given population all or area if interest factuality and accurately descriptive method is suitable of the topic.

Therefore, the writer intended to describe the data systematically and then to analyze them as accurately as possible. In this investigation, the writer took the data concerning with the tenth eleventhgrade students of social programof tenseserrors in writing recount text at Senior High School Number 1MuaraBeliti and Senior High School Number 2MuaraBeliti. The writer gave the test item directly and analyze the students' composition, after that the writer described the students' tenses errors in writing recount text. 


\section{Subject of the Reserch}

Subject of the research referred to the subject who would be observed. In this study, subject of the investigation was the eleventh eleventhgrade students of social programSenior High School Number 1 and Senior High School Number 2 MuaraBelitiin academic year 2016/2017. The total students for subject of the investigation were178 students. It was presented in the following table.

Table 1 Subject of the Investigation

\begin{tabular}{lc}
\hline \multicolumn{2}{l}{ Senior High School 1 MuaraBeliti } \\
\hline XI.IISA & $: 28$ \\
XI.IISB & $: 29$ \\
XI & $: 30$ \\
TOTAL & $: 87$ \\
Senior High School 1 MuaraBeliti \\
\hline XI.IISA & $: 30$ \\
XI.IISB & $: 31$ \\
XI & $: 30$ \\
TOTAL & $: 91$ \\
\hline
\end{tabular}

The writer chose the subject of the investigation by using simple random sampling. According to Fraenkel and Wallen (1991:132), Simple random sampling is one in which each and every member of the population has and equal chance of being selected. The writer chose simple random sampling, because the writer had to take five students each classes of each school. The total of sample was 30 students.

\section{Technique for Collecting the Data}

In this investigation, the writer used a written test for collecting the data. The test used to know the students' tenses errors. Heaton (1988:8), writing ability usually is in the form of letters, report, memos, messages, instruction, and account of past even, etc. The other word, the writer got instruction as the suitable form of the test. According to Brown (1980:219), Test is a method of measuring a person ability or knowledge in a given area. The students built a written production depend on instruction given by the writer. The writer asked the students to make a recount text about unforgettable experience 150 words in a paper with time allocation 45 minutes in doing them. The test used to identify the students made errors in grammatical in recount text . 


\section{Technique for Analyzing Data}

In analyzing the data of the test, the writer focused on error analysis in the usage of tenses in recount paragraph. In order to know the individual errors, the writer described the students errors in writing of text recount based on the following steps :

1. Identifying the students' recount text and found out what were kinds their errors in writing of text recount.

2. Classifying the students' tenses errors in writing paragraph. Therefore, the data will be categorized into each kind of error.

3. Describing the students' tenses errors made by the students in writing recount text.

4. Calculating the tenses errors that made by the students. Based on the classifying of the errors in using recount text. The writer wanted to know the tenses errors by using the formula below :

$$
\mathrm{P}=\frac{F}{N} \times 100 \%
$$

Where :

$\mathrm{P}=$ the percentages of errors

$\mathrm{F}=$ total number of students errors

$\mathrm{N}=$ all the students sample (Sudijono, 2004:43)

\section{FINDING}

The result of Tenses Errors in Writing Recount Text Made by the Eleventh Grade Students Of Social ProgramSenior High School Number 1

In this part, the writer explained the dominant tenses errors in writing of textrecount made by students. Based on the table error analysis, there were 112 sentences from 15 students. From the table below, there were 62 or $55.36 \%$ in verb tenses, 5 or $4.46 \%$ in pronoun, 6 or $5.35 \%$ in preposition, and 39 or $34.83 \%$ in punctuation and spelling. It was the dominant tenses error in writing recount text made by the eleventhgrade students of social program. The table was about the dominant tenses error.

Table 2. The Dominant of Students' Tenses Errors

\begin{tabular}{lll}
\hline Tenses & $: 62$ & $(55.36 \%)$ \\
\hline Pronoun & $: 5$ & $(4.46 \%)$ \\
\hline Preposition & $: 6$ & $(5.35 \%)$ \\
\hline Punctuation and spelling & $: 39$ & $(34.83 \%)$ \\
\hline Total & $: 112$ & $(100 \%)$ \\
\hline
\end{tabular}


The Result of Tenses Errors in Writing Recount Text Made by the Eleventh Grade Students Of Social Program of Senior High School Number 2 Muara Beliti.

In this part, the writer explained the dominant tenses errors in writing recount text made by students. Based on the table error analysis, there were 172 sentences from 30 students. From the table below, there were 37 or $61.67 \%$ in verb tenses, 1 or $1.66 \%$ in pronoun, 1 or $1.66 \%$ in preposition, and 21 or $35.01 \%$ in punctuation and spelling. It was the dominant tenses error in writing recount text made by the eleventhgrade students of social program. The table was about the dominant tenses error.

Table 3. The Dominant of Students' Tenses Errors

\begin{tabular}{lll}
\hline Tenses & $: 37$ & $(61.67 \%)$ \\
\hline Pronoun & $: 1$ & $(1.66 \%)$ \\
\hline Preposition & $: 1$ & $(1.66 \%)$ \\
\hline Punctuation and spelling & $: 21$ & $(35.01 \%)$ \\
\hline Total & $: 60$ & $(100 \%)$ \\
\hline
\end{tabular}

\section{DISCUSSION}

The result of the study that was explained previously showed information's related to the recount text that was made by the students. In chapter 2 had discussed which is in this study tenses in writing skills, that would be analyzed especially in tenses in writing skills.

\section{Chart 1. The Dominant Tenses Errorsboth of Senior High School Number 1Muara Beliti and SMA Negeri 2 MuaraBeliti}

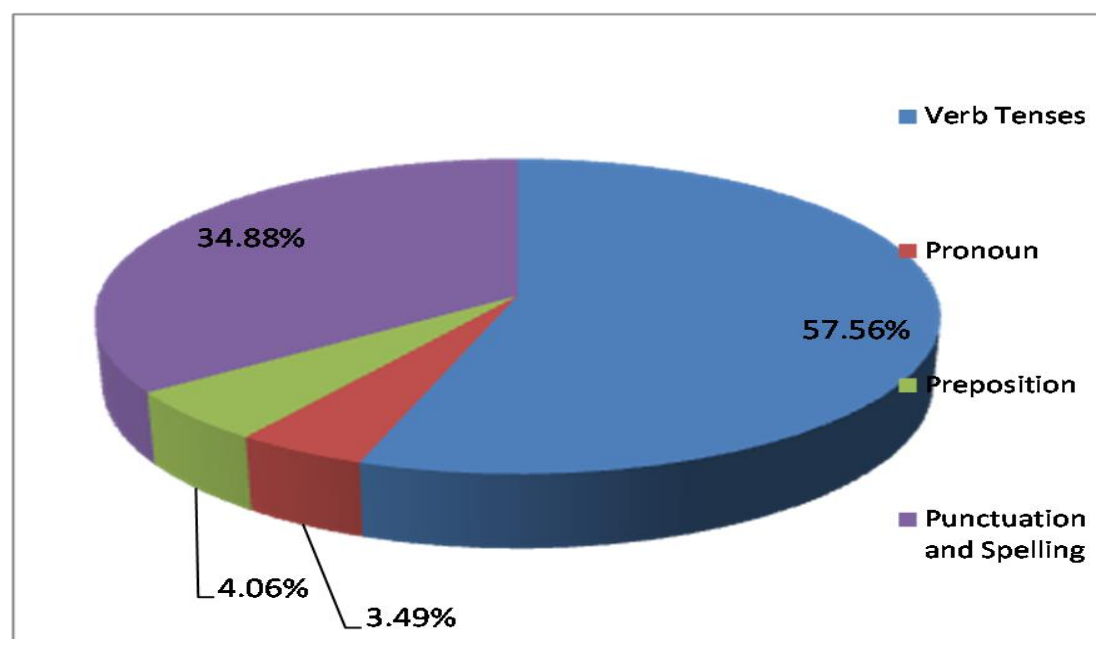


Based on the findings on students errors. The writer found the percentages of common errors of tenses aspect. The percentages of common errors of tenses were verb tenses $(57.56 \%)$, pronoun $(3.49 \%)$, preposition $(4.06 \%)$, and punctuation and spelling $(34.88 \%)$. The most category of error done by students were tenses, where they could not the past tense form, and they could not the changing verb. Sometimes, they forget to distinguish the verb which one one regular and irregular. Punctuation and spelling could be caused they could not spell and write some English word correctly because she was interfered by Indonesian language, and could not correctly in capitalization proper names of place, and the student do capitalization in a center sentences.

Pronoun could be caused they could not differentiate between nominative, subjective pronoun and objective pronoun, because they was interfered by Indonesian language. In Indonesian language there's no pattern of using the personal pronoun. Preposition could be caused they did not use preposition before a noun as making prepositional phrase of time. Beside that, according to Brown (2000:223), there were four sources of errors. They were: intralingua transfer, interlingua transfer, context of learning, and communication strategies. The writer determined that the sources of errors in tenses error in writing recount text made by students was Interlingua transfer.

Based on more description above, the influence of errors was caused by the difficulties in learning foreign language. Finally, as the result the students' made such errors because the influence of linguistic mother tongue and their Indonesian logical thinking. They thought in Indonesian way when they wrote in English. However, when they processed the new language data in their mind, it also produces a new rules, so they often over generalize about their second language rules. It means the teacher should aware that intra-lingual transfer is one of the sources of error that must be recognized in second language learning.

\section{CONCLUSION}

Based on the finding and discussion in the previous chapter about students made some tenses errors in writing of text recount. It can be seen from the result of data analysis. The writer has drawn the conclusion by presenting and the percentages of classification of tenses errors follows: it was found that the majority errors don ethe eleventhgrade students of social program of Senior High School Number 1MuaraBeliti was Verb $(55.36 \%)$ total errors was 62 . The second position was punctuation and spelling $(4.46 \%)$ total errors was 5 . The third position was preposition $(5,35 \%)$ total errors 6 . And the last position was pronoun (34.83\%) total errors was39.The majority errors done the eleventhgrade students of social program of Senior High School Number 2MuaraBelitiwasVerb (61.67\%) total errors was 37. The second position was punctuation and spelling (1.66\%) total errors was 1 . The third position was preposition $(1.66 \%)$ total errors was1. And the last position was pronoun $(35.01 \%)$ total errors was 21 . Which the students made errors cause by the wrong place of verb or sentence and theirs mother tongue interference. 


\section{REFERENCES}

Brown, H.D. (1980). Principles of Language Learning and Teaching. White Plains, New York: Prentice-Hall Inc.

- (2000). Principles of Language Learning and Teaching. White Plains, New York: Prentice-Hall Inc.

Corder.S.P. (1982). Error Analysis and Interlanguage. London. Oxford University.

Ellis, R. (1997). Understanding Second Language Acquisition. New York: Oxford University Press.

Grenville, K. (2001). Writing from Start to Finish: A Six-Step Guide. Crows NestAustralia: National Library of Australia.

Frenkel, J.R \& N.E Wallen. (1991). How to Design and Evaluate Research in Education. New York, NY: McGraw-Hill, Inc.

Harmer, J. (2012). The Practice of English Language Teaching . London: Longman

Heaton, J.B. (1988). Writing English Language Test. London: Longman.

Hornby, A S. (1987). Oxford Advanced Learner's Dictionary of Current English. Walton Street, Oxford: Oxford University Press.

Isaac, S. \& W. B. Michael. (1985). Handbook in Research and Evaluating. Sandiego, CA:Ediths Publisher

James, C. (1998). Errors in Language Learning and Use;ExploringErrorAnalysis. London and New york: Addison Wesley Longman Limited.

Kreml, N.M. (2004). The User's Guide to College Writing: Reading,Analyzing, andWriting. 2nd ed.New York: Pearson Education, Inc

Norrish, J. (1987). Language Learning and their Errors.London: Macmillan Publisher Ltd.

Nunan, D. (2003). Language Teaching Metodnology; A text Book for A Teacher. New York: Prentice Hall

Oshima, A. (1991).Writing Academic English. 3rd ed. New York: Addison Wesley Longman.

Richards, J.C.(1973). Error Analysis.London: Longman. . (2002). Longman Dictionary of applied linguistic. Hongkong: Longman GroupLimited.

Sudijono, A. (2004). Pengantar Statistik Pendidikan. Jakarta: PT Raja Grafindopersada. 